\title{
Protein Intake in Infancy and Carotid Intima Media Thickness at 5 Years - A Secondary Analysis from a Randomized Trial
}

\author{
Dariusz Gruszfeld $^{\mathrm{a}}$ Martina Weber ${ }^{\mathrm{b}}$ Monika Nowakowska-Rysz ${ }^{\mathrm{a}}$ Roman Janas ${ }^{\mathrm{a}}$ \\ Rainer Kozlik-Feldmann ${ }^{b}$ Annick Xhonneux ${ }^{c}$ Clotilde Carlier $^{d}$ Enrica Riva ${ }^{\mathrm{e}}$ \\ Elvira Verduci $^{\mathrm{e}}$ Ricardo Closa-Monasterolo ${ }^{f}$ Joaquin Escribano ${ }^{f}$ Anna Dobrzanska ${ }^{a}$ \\ Berthold Koletzko ${ }^{b}$ for the European Childhood Obesity Study Group \\ ${ }^{a}$ Children's Memorial Health Institute, Warsaw, Poland; ${ }^{b}$ Dr. von Hauner Children's Hospital, University of Munich Medical \\ Centre, Munich, Germany; ${ }^{C} \mathrm{CHC}$ Saint Vincent, Liège-Rocourt, and d University Children's Hospital Queen Fabiola,

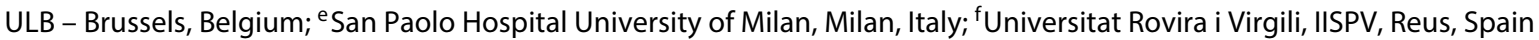

\section{Key Words}

Proteins and amino acids · Cardiovascular health · Infancy and childhood · Lipids · Obesity

\begin{abstract}
Background: Nutrition in childhood has an influence on the cardiovascular function later on in life. European Childhood Obesity Project is a multicenter, randomized clinical intervention trial examining the effect of early protein intake on later health outcomes, particularly adiposity and related disorders. The aim of the study was to examine the effect of nutritional intervention - different protein intake in infancy on carotid intima-media thickness (cIMT) at 5 years. The association of cardiovascular risk factors with cIMT was also assessed. Methods: Healthy term formula-fed infants in five European countries were enrolled either to the higher (HP) or to the lower (LP) protein group. Observational group consisted of breastfed infants. Plasma insulin, glucose, lipid profile, IGF-1, apolipoprotein A1 and B were measured as well as anthropometric parameters of parents and a child, blood
\end{abstract}

pressure and physical activity. Results: No difference in cIMT between HP and LP group was observed. Insulin, HOMA-IR index and total IGF-1 were positively associated with CIMT but after adjustment for confounders only an inverse association between ApoA1 and positive between ApoB/ApoA1 and cIMT were significant. Conclusion: High versus low protein intake in infancy does not influence cIMT at 5 years. CIMT in healthy children at 5 years is associated with their apolipoprotein profile.

(c) 2015 S. Karger AG, Basel

European Childhood Obesity Project Group: Beyer J., Fritsch M, Haile G., Handel U., Hannibal I., Kreichauf S., Pawellek I., Schiess S., Verwied-Jorky S., von Kries R. (Children's University Hospital, University of Munich Medical Centre, Munich, Germany), Ferré N., Gispert-Llaurado M., Luque V., Mendez-Riera G., Rubio-Torrents M.C., Zaragoza-Jordana M. (Pediatrics Unit, Universitat Rovira i Virgili, IISPV, Reus, Spain), Janas R., Wierzbicka A., Stolarczyk A., Socha J., (Children's Memorial Health Institute, Warsaw, Poland), Dain E., Van Hees J.N., Hoyos J., Martin F., Poncelet P., (ULB Bruxelles and CHC St. Vincent Liege), Perrin E. (Danone Research Centre for Specialised Nutrition, Schiphol, The Netherlands), Agostoni C., Giovannini M., Re Dionigi A., Riva E., Scaglioni S., Vecchi F. (University of Milan).

\section{KARGER 125}

(c) 2015 S. Karger AG, Base

0250-6807/15/0661-0051\$39.50/0

E-Mail karger@karger.com

www.karger.com/anm
Dariusz Gruszfeld, MD, PhD

Children's Memorial Health Institute

NICU, 04-730 Al, Dzieci Polskich 20

Warszawa (Poland)

E-Mail d.gruszfeld@czd.pl 


\section{Introduction}

Arteriosclerotic alterations progress from childhood over to adulthood. The association to multiple risk factors like unfavorable lipid profile, body weight, blood pressure and diabetes is well studied in adults but less is known about this in children [1].

Arteriosclerosis has a long, asymptomatic, preclinical period. Pathological changes in the arteries of children develop decades before clinical manifestation of the disease. Some authors suggest that specific types of lesions occurring in younger ages (fatty streaks) are transformed into another type of lesions (fibrous plaques) in young adults and middle-aged persons, while others demonstrate that the progression from fatty streaks to plaque might be arrested in childhood and does not begin to a significant extent until after puberty in males and after menopause in females $[2,3]$.

Autopsy studies on arterial specimens of human subjects have shown that fatty streaks can be found even in the aortas of 3-year-old children [4]. In The Bogalusa Heart Study coronary artery changes were found in children as early as in the first decade of life [5]. These findings have been confirmed later in other populations, and extended to arteriosclerosis at different vascular sites [6].

Nutrition in childhood has an influence on the risk of arteriosclerosis independently of the known risk factors in adults [7]. In an observational study of 306 children at 5 years of age in the Netherlands, carotid intima media (cIMT) was significantly thicker in children who had been exclusively breastfed in infancy for 3-6 months [8] In adults several dietetic intervention studies improving the serum lipid profile by diet have shown an association with reduced severity of coronary heart disease [9]. However, there is a lack of intervention studies in early childhood with subsequent follow-up into later ages.

In the European Childhood Obesity Project (CHOP) we demonstrated that higher protein intake during the first year of life may increase the risk of overweight and obesity later at the age of $6[10,11]$. Obesity is known to be associated with several cardiovascular risk factors including dyslipidemia, hyperinsulinemia, hypertension and early arteriosclerosis in adults and children $[12,13]$.

Evelein et al. demonstrated in healthy young children that excess early postnatal weight gain, which was also observed in CHOP, leads to thicker arterial walls at 5 years of age [14].

In addition, the different protein content in study formulas used in the project was compensated by total fat to achieve their identical energy contents, which might independently affect long-term arteriosclerotic risk.

Finally, insulin-like growth factor 1 (IGF-1), which was increased in infants from 'higher protein' intake group, may also affect the arteriosclerotic process by exerting an antiapoptotic effect on vascular smooth muscles end endothelial cells $[15,16]$.

The main purpose of the study reported herein was to examine the effect of the early nutritional intervention on carotid intima media thickness - a marker for subclinical arteriosclerotic disease - at five years of age. The secondary aim was to analyze the relationship between risk factors for cardiovascular disease and carotid intima-media thickness.

\section{Methods}

Study Design

The detailed design of the CHOP study was published previously [10]. Briefly, it is a double-blind, randomized, multicenter, prospective nutritional intervention trial in infants, conducted in Belgium, Germany, Italy, Poland and Spain. Children were enrolled during the first eight weeks of life. Formula-fed (FF) infants were randomized in two intervention groups and breastfed (BF) infants were included as a reference group. All children were followed-up to the age of six years.

The study was approved by the ethic committees of all study centers. Written informed parental consent was obtained for each infant.

\section{Intervention}

The intervention consisted of two sets of infant and follow-on formulas with either higher (2.05 and $3.2 \mathrm{~g} / \mathrm{dl}$; HP) or lower $(1.25$ and $1.6 \mathrm{~g} / \mathrm{dl}$; LP) protein content given to the infants during the first year of life. All formulae complied with the $1991 \mathrm{EU}$ Directive on Infant and Follow-on Formulae [17]. Identical energy density was achieved by adapting the difference in protein content with fat. $\mathrm{BF}$ infants had to be exclusively breastfed for at least three months.

Study Population

Apparently healthy, singleton, term infants born between October 1st 2002 and July 31st 2004, were recruited in the 11 sites of the study centers in Germany (Munich and Nuremberg), Belgium (Liege and Brussels), Italy (4 sites in Milano), Poland (Warsaw) and Spain (Reus and Tarragona). At recruitment, breastfeeding was promoted and supported. A total of 1,678 infants (540 LP, $550 \mathrm{HP}, 588 \mathrm{BF}$ ) were enrolled in the original study (median age at the baseline visit was 16 days). Clinical characteristics of all study participants at study entry were published previously [10].

\section{Data Collection}

Birth weight and length were obtained from hospital data. Afterwards all anthropometric measures were taken by a trained study personnel at the baseline visit, at three, six, twelve, 24 months of age, and biannually until the age of six years following standard operating procedures based on the World Health Organization (WHO) Growth Multicentre Reference study [18]. 
cIMT was measured during the visit at 5 years of age. All children coming to the study visit were offered to have cIMT evaluated but not all families accepted an additional and time-consuming procedure. The combined thickness of the intimal and medial arterial wall components of the common carotid artery was determined with a linear transducer by a trained member of the medical staff. Subjects were examined in a supine position with a slightly overextended neck in a two-dimensional presentation of the longitudinal view of the vessel. cIMT of the far wall was measured $1-2 \mathrm{~cm}$ below the bifurcation of the common carotid artery at the late diastolic phase. At least one image for the right and one for the left artery from each subject was recorded, saved in JPG format, and transferred to the Children's Memorial Health Institute in Warsaw, Poland.

The following ultrasound devices were used in the different sites:

- Belgium: Siemens Sonoline Antares, Siemens Medical Solution USA, Mountain View, Calif., USA, 5.0-10.0 MHz (Brussels); ATL Philips HDI 5000, Bothell, Wash., USA, 5.0-12.0 MHz (Liege);

- Germany: Philips iE33, Philips GmbH, Hamburg, Germany, 11-13 MHz;

- Italy: GE Logiq 9, GE Healthcare Medical System, Milwaukee, Wisc., USA, 10-12 MHz;

- Poland: Vivid Pro 7, GE Vingmed Ultrasound, Horten, Norway, 8-13 MHz;

- Spain: Acuson Antares System, Siemens Medical Solutions USA, Mountain View, Calif., USA, 5-10 MHz (Reus); Acuson Sequoia 512 TM, Siemens Medical Solutions USA, Mountain View, Calif., USA, 8-15 MHz (Tarragona).

Measurements with a manual cursor placement method were performed by a blinded, trained physician on the pictures from all centers. Especially dedicated software was created to firstly, calibrate the ruler based on two points with $1 \mathrm{~cm}$ distance visible on the scale of the picture; secondly, to perform three measurements on each picture and calculate a mean value for the right and left artery. For analysis, the sum of left and right cIMT divided by two, alternatively left or right measurement in case of only one good quality picture, was used.

At the same visit at 5 years, blood pressure was measured by an oscillometric technique with Dinamap Procare blood pressure monitor (GE Medical Systems, Freiburg, Germany).

Social economics, family medical history, physical activity of the study children, and maternal behavior during pregnancy were assessed by specially designed questionnaires.

At 5 $\frac{1 / 2}{2}$ years a fasted venous blood sample was drawn from all children that agreed for the procedure. Serum samples were stored at $-70^{\circ} \mathrm{C}$ and transported on dry ice to the central laboratory (The Children's Memorial Health Institute, Warsaw, Poland) for analysis of IGF-axis parameters, apolipoprotein A1 (ApoA1) and apolipoprotein $\mathrm{B}(\mathrm{ApoB})$. The variables of the IGF-axis were measured with the use of immunoradiometric assay (Diagnostic Systems Laboratories Inc., Webster, Tex., USA). Serum insulin levels were quantified using immunoradiometric assay (DiaSource, Nivelles, Belgium). Fasting insulin and glucose was used to estimate insulin resistance by the homeostasis model of assessment of insulin resistance (HOMA-IR index) [19]. ApoA1 and ApoB were determined by an automated immunoturbidimetric method using polyclonal antisera (Orion Diagnostica, Espoo, Finland). Glucose, total cholesterol, high-density lipoprotein cholesterol -
HDL cholesterol, low-density lipoprotein cholesterol - LDL cholesterol and triglycerides (TG) were analyzed in the respective laboratories of the local study centers. An enzymatic method was used for determination of total cholesterol, HDL cholesterol, LDL cholesterol and TG. An enzymatic reference method with hexokinaze or indirect potentiometry (Reus, Spain) was used for glucose measurement.

\section{Statistical Methods}

Symmetric continuous data is presented as the mean \pm standard deviation (SD), skewed continuous and count data as median and inter quartile range [IQR]. Comparisons between the feeding groups were performed using Student's t test, Wilcoxon rank sum tests or $\chi^{2}$-tests, respectively. Spearman correlation coefficients between cIMT values and selected risk factors were calculated and tested for significance. Linear regression models on log-transformed cIMT measurements were applied to adjust for possible confounders (country, gender, type of feeding and smoking of the mother during pregnancy). The study had a sufficient power (80\%) to detect a difference in cIMT between the two formula groups.

Data management was carried out with SAS version 9.2 (SAS Institute Inc., Cary, N.C., USA) and statistical analysis with R 2.10.1 (The R Foundation for Statistical Computing).

\section{Results}

Of the randomized 1,090 formula-fed children, 528 (48\%) were followed until 5 years of age. Dropout numbers and the reasons for dropout were not significantly different between the two randomized groups. Additional $16 \%(n=178)$ of all randomized, formula-fed children were excluded for noncompliance, illness or medication. Loss to follow-up was higher in the observational breastfed group (fig. 1). The overall mean age at the 5 years visit was $5.03( \pm 0.05)$.

Characteristics of the population at 5 years of age differed slightly from the original study population, that is, children of parents with higher educational background were more likely to stay in the study [10]. Breastfed infants differed from formula-fed in terms of socioeconomic status, prevalence of pregnancy smoking, and parental BMI. However, no differences between the two randomized formula groups were observed.

Comparison of the subgroup of children who underwent cIMT measurement $-52 \%(\mathrm{n}=403)$ with those who did not give their consent $-48 \%(\mathrm{n}=368)$ did not demonstrate any significant differences in educational status of parents, smoking behavior, parental and child BMI, blood pressure, physical activity, insulin, glucose or lipid parameters (data not shown).

Detailed clinical characteristics of the subgroup with ultrasound measurement are listed in table 1 . 


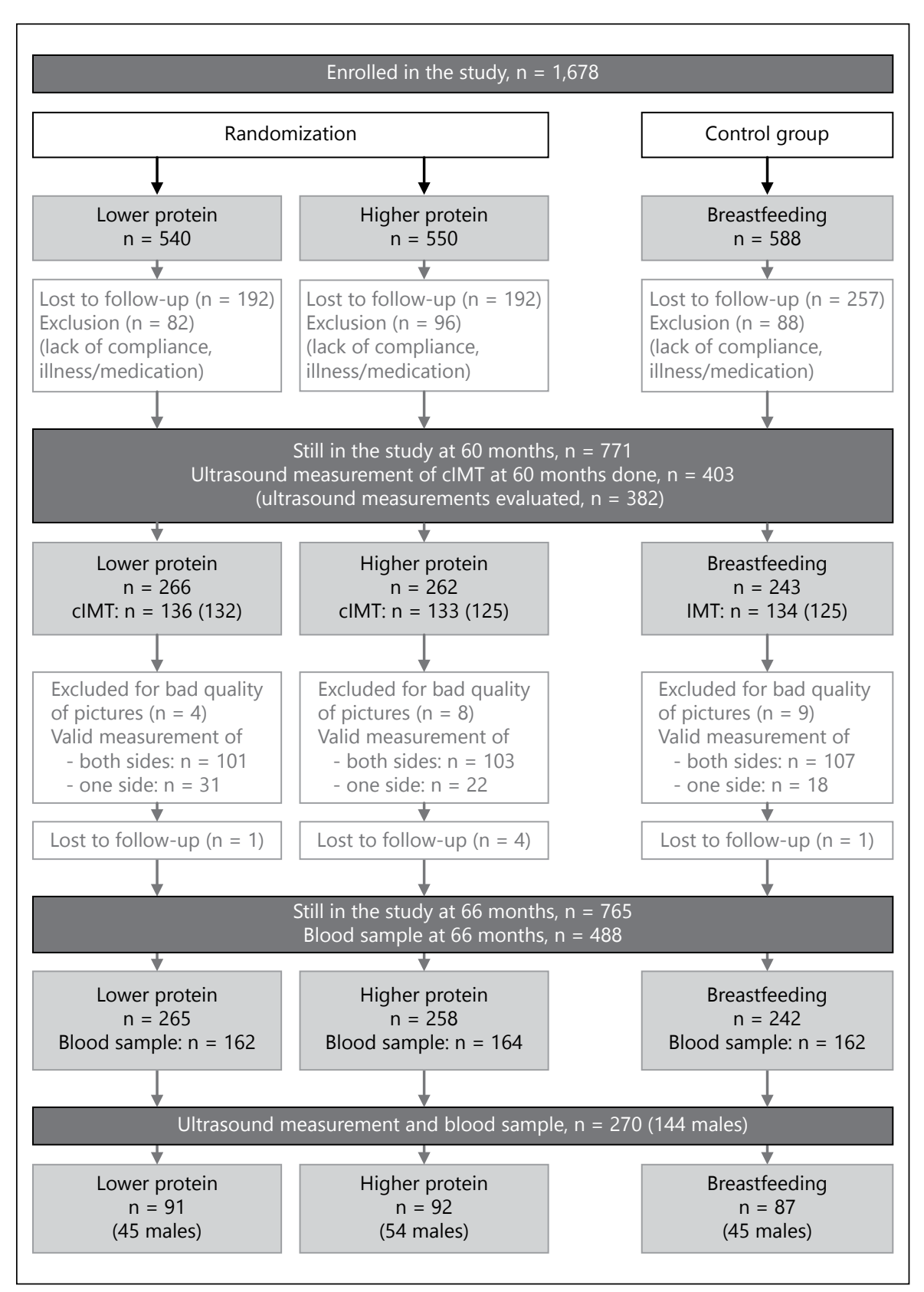

Fig. 1. Randomization, allocation and study participation.

\section{Comparison by Feeding Groups}

Table 2 summarizes cIMT measurements by feeding groups. No significant differences in cIMT between the formula feeding groups were found. There was no difference between formula fed and breastfed children, either.

\section{Associations with Risk Factors}

We found an association between cIMT and total IGF-1 $(\mathrm{R}=0.12 ; \mathrm{p}=0.04)$, insulin $(\mathrm{R}=0.16 ; \mathrm{p}=0.01)$ and HOMA-IR index $(\mathrm{R}=0.16 ; \mathrm{p}=0.01)$.
There was also an inverse association between cIMT and ApoA1 $(\mathrm{R}=-0.16 ; \mathrm{p}=0.01)$ and a positive association with $\mathrm{ApoB}(\mathrm{R}=0.13 ; \mathrm{p}=0.02)$ and $\mathrm{ApoB} / \mathrm{ApoA} 1$ ratio $(\mathrm{R}=0.15 ; \mathrm{p}=0.01)$ (table 3 ). The association between ApoA1, ApoB/ApoA1 ratio and cIMT was significant also after adjustment for country, gender and feeding group.

On the contrary, no association was observed between cIMT and anthropometric parameters of neither the parents nor the child. Blood pressure, glucose, total choles- 
Table 1. Population characteristics

\begin{tabular}{|c|c|c|c|c|c|c|}
\hline & \multicolumn{2}{|c|}{ Higher protein (HP) } & \multicolumn{2}{|c|}{ Lower protein (LP) } & \multicolumn{2}{|c|}{ Breastfed (BF) } \\
\hline & $\mathrm{n}$ & $\begin{array}{l}\text { mean } \pm \mathrm{SD} \\
\text { median }[\mathrm{IQR}] \\
\mathrm{n}(\%)\end{array}$ & $\mathrm{n}$ & $\begin{array}{l}\text { mean } \pm \mathrm{SD} ; \\
\text { median }[\mathrm{IQR}] \\
\mathrm{n}(\%)\end{array}$ & $\mathrm{n}$ & $\begin{array}{l}\text { mean } \pm \mathrm{SD} ; \\
\text { median }[\mathrm{IQR}] \\
\mathrm{n}(\%)\end{array}$ \\
\hline Mother's BMI, kg/m² & 133 & $24.7 \pm 4.9$ & 135 & $23.9 \pm 4.3$ & 134 & $22.9 \pm 4.3^{* *}$ \\
\hline Father's BMI, kg/m² & 132 & $26.6 \pm 3.7$ & 136 & $26.2 \pm 4$ & 133 & $25.7 \pm 3.4$ \\
\hline Birth weight, kg & 133 & $3.3 \pm 0.4$ & 136 & $3.3 \pm 0.3$ & 134 & $3.4 \pm 0.3$ \\
\hline Birth length, $\mathrm{cm}$ & 132 & $51.1 \pm 2.8$ & 135 & $50.6 \pm 2.5$ & 134 & $51 \pm 2.6$ \\
\hline Weight at 5 years, $\mathrm{kg}$ & 127 & $20.1 \pm 3.6$ & 133 & $19.5 \pm 2.6$ & 128 & $19.2 \pm 2.9^{* *}$ \\
\hline Height at 5 years, $\mathrm{cm}$ & 125 & $110.4 \pm 4.6$ & 133 & $110.8 \pm 4.2$ & 128 & $110 \pm 4.8$ \\
\hline BMI at 5 years, $\mathrm{kg} / \mathrm{m}^{2}$ & 124 & $16.4 \pm 2.1$ & 133 & $15.9 \pm 1.6^{*}$ & 128 & $15.8 \pm 1.5^{* *}$ \\
\hline Overweight, \% & 124 & $14(11.3)$ & 133 & $13(9.8)$ & 128 & $12(9.4)$ \\
\hline Hypertension, \% & 113 & $11(9.7)$ & 119 & $11(9.2)$ & 117 & $9(7.7)$ \\
\hline IGF-1, ng/dl & 103 & $118[83.8 ; 156.5]$ & 104 & $116[88.2 ; 145.2]$ & 104 & $115.5[88.4 ; 154.2]$ \\
\hline Insulin, $\mu \mathrm{IU} / \mathrm{ml}$ & 103 & $6[4.5 ; 7.6]$ & 104 & $5.6[4.4 ; 7.5]$ & 104 & $5.5[4.5 ; 7.1]$ \\
\hline Total cholesterol, mg/dl & 104 & $166[150 ; 181.2]$ & 104 & $171.5[150 ; 186.2]$ & 105 & $158[142 ; 170]^{* *}$ \\
\hline LDL cholesterol, mg/dl & 102 & $103[86.5 ; 114]$ & 103 & $101[887 ; 117.5]$ & 104 & $91[78.8 ; 107.5]^{* *}$ \\
\hline HDL cholesterol, mg/dl & 103 & $53[46 ; 62]$ & 104 & $53[44 ; 61]$ & 104 & $52[45 ; 59]$ \\
\hline Triglyceride, mg/dl & 104 & $52.5[38 ; 77.5]$ & 104 & $50.5[42.8 ; 73.8]$ & 105 & $54[43 ; 70]$ \\
\hline ApoB, g/l & 103 & $0.9[0.7 ; 1.1]$ & 104 & $0.9[0.7 ; 1.1]$ & 104 & $0.8[0.6 ; 1]$ \\
\hline ApoB/ApoA1 & 103 & $0.6[0.5 ; 0.9]$ & 104 & $0.6[0.5 ; 0.8]$ & 104 & $0.6[0.5 ; 0.8]$ \\
\hline ApoA1, g/1 & 103 & $1.4[1.3 ; 1.6]$ & 104 & $1.4[1.3 ; 1.5]$ & 104 & $1.4[1.2 ; 1.6]$ \\
\hline
\end{tabular}

${ }^{*} \mathrm{p}<0.05$ for HP vs. LP; ${ }^{* *} \mathrm{p}<0.05$ for formula fed vs. breastfed.

Table 2. cIMT by feeding group

\begin{tabular}{|c|c|c|c|c|c|c|c|c|}
\hline & $\mathrm{n}$ & $\begin{array}{l}\operatorname{cIMT}(\mathrm{mm}) \\
\text { median }[\mathrm{IQR}]\end{array}$ & $\mathrm{n}$ & $\begin{array}{l}\text { cIMT (mm) } \\
\text { median [IQR] }\end{array}$ & $\begin{array}{l}\text { p value } \\
\text { HP vs. } \\
\text { LP }\end{array}$ & $\mathrm{n}$ & $\begin{array}{l}\operatorname{cIMT}(\mathrm{mm}) \\
\text { median [IQR] }\end{array}$ & $\begin{array}{l}\mathrm{p} \text { value } \\
\text { formula } \\
\text { fed vs. BF }\end{array}$ \\
\hline All & 125 & $0.38[0.32 ; 0.45]$ & 133 & $0.39[0.33 ; 0.5]$ & n.s. & 125 & $0.4[0.34 ; 0.49]$ & n.s. \\
\hline Boys & 72 & $0.38[0.32 ; 0.45]$ & 61 & $0.4[0.33 ; 0.5]$ & n.s. & 62 & $0.4[0.34 ; 0.49]$ & n.s. \\
\hline Girls & 53 & $0.37[0.32 ; 0.45]$ & 72 & $0.38[0.32 ; 0.48]$ & n.s. & 63 & $0.39[0.34 ; 0.48]$ & n.s. \\
\hline
\end{tabular}

n.s. $=$ Not significant.

terol, HDL-cholesterol, LDL-cholesterol and TG, which are all associated to cIMT in adulthood, showed no correlation at the age of 5 years.

cIMT measures did not significantly vary neither between boys and girls nor between the children of smoking and non-smoking mothers.

\section{Discussion}

\section{Main Findings}

To our knowledge this is the first report from randomized nutritional intervention trial in healthy, adequate for gestational age infants focused on subclinical arterioscle- 
Table 3. Spearman correlations of cIMT with potential arteriosclerotic risk factors

\begin{tabular}{|c|c|c|c|c|c|c|}
\hline & \multicolumn{2}{|l|}{ All } & \multicolumn{2}{|c|}{ Boys } & \multicolumn{2}{|c|}{ Girls } \\
\hline & $\mathrm{n}$ & $\begin{array}{l}\text { Spearman } \\
\text { correlation } \mathrm{R}\end{array}$ & $\mathrm{n}$ & $\begin{array}{l}\text { Spearman } \\
\text { correlation } \mathrm{R}\end{array}$ & $\mathrm{n}$ & $\begin{array}{l}\text { Spearman } \\
\text { correlation } \mathrm{R}\end{array}$ \\
\hline \multicolumn{7}{|l|}{ Perinatal factors } \\
\hline Mother's BMI, kg/m² & 381 & 0.00 & 195 & 0.03 & 186 & -0.04 \\
\hline Father's BMI, $\mathrm{kg} / \mathrm{m}^{2}$ & 380 & -0.08 & 194 & -0.12 & 186 & -0.04 \\
\hline \multicolumn{7}{|l|}{ Lifestyle } \\
\hline Hours spent playing outside & 308 & 0.05 & 154 & 0.08 & 154 & -0.02 \\
\hline Hours spent watching TV/playing video games & 296 & -0.08 & 148 & -0.14 & 148 & -0.02 \\
\hline \multicolumn{7}{|l|}{ Child's physiological markers at 5 years } \\
\hline Diastolic blood pressure, $\mathrm{mm} \mathrm{Hg}$ & 334 & 0.06 & 168 & 0.03 & 166 & 0.07 \\
\hline \multicolumn{7}{|l|}{ Child's biochemical markers at $5 \frac{1}{2}$ years } \\
\hline IGF-1, ng/dl & 297 & $0.12^{*}$ & 156 & 0.15 & 141 & 0.11 \\
\hline Total cholesterol, mg/dl & 298 & -0.04 & 154 & 0.01 & 144 & -0.08 \\
\hline LDL cholesterol, mg/dl & 294 & -0.04 & 151 & 0.00 & 143 & -0.09 \\
\hline HDL cholesterol, mg/dl & 296 & 0.08 & 152 & 0.07 & 144 & 0.08 \\
\hline Triglyceride, $\mathrm{mg} / \mathrm{dl}$ & 298 & -0.06 & 154 & -0.06 & 144 & -0.06 \\
\hline Insulin, $\mu \mathrm{IU} / \mathrm{ml}$ & 297 & $0.16^{*}$ & 156 & $0.19^{*}$ & 141 & 0.13 \\
\hline HOMA-IR index & 290 & $0.16^{*}$ & 151 & $0.22 *$ & 139 & 0.09 \\
\hline ApoB, g/l & 297 & $0.13^{*}$ & 156 & 0.15 & 141 & 0.11 \\
\hline ApoA1, g/l & 297 & $-0.16^{*, \S}$ & 156 & -0.16 & 141 & $-0.17^{*}$ \\
\hline
\end{tabular}

${ }^{*} \mathrm{p}<0.05 ;{ }^{\S} \mathrm{p}<0.05$ adjusted for country, gender, feeding group.

rosis in early childhood. Although at 5 years of age no differences in cIMT between the HP and LP group could be observed it cannot be excluded that longer time is needed for the development of detectable cIMT diversity.

At the same age of 5 years an association between cIMT and several risk factors was evaluated. Child's and parental anthropometrics, life style/environmental factors and blood pressure were not correlated with cIMT. Nevertheless, ApoA1 and ApoB/ApoA1 ratio were significantly associated with cIMT while lipoprotein cholesterol was not.

\section{Comparison with Other Studies and Implications}

We did not confirm the observation from WheezingIllnesses-Study-Leidsche-Rijn (WHISTLER) birth cohort study, that demonstrated a difference in cIMT between breastfed and formula-fed children. However, it is worth noting, that the breastfed group was not randomized [8].
The present study also did not confirm any long-term association of pregnancy smoking with carotid intima media thickness at 5 years. Such a relationship could be expected based on other studies, which demonstrated significantly increased aortic IMT in neonates whose mothers smoked during pregnancy [20]. It might be that ultrasound measurement of the aorta in newborns does not represent the situation in other arteries, especially at a later age.

Similarly, no association of cIMT was found with physical activity in our study, although in older Japanese children, aged 6-14, the lifestyle assessed by questionnaires (hours of TV watching, hours of sleeping) had an impact on cIMT [21].

Also obesity was reported by a number of observational studies to be associated with increased cIMT [22]. In our analysis no association with child's anthropometry 
was detected, but contrary to other studies our cohort consisted of healthy, adequately-nourished children, with low prevalence of obesity ( $4.5 \%$ obese; $10.2 \%$ overweight) [23].

Although increased blood pressure is a known cardiovascular risk factor [24] we did not find an association between cIMT and blood pressure; however, our cohort consisted of younger children than those from other reports [25]. An elevated blood pressure above 95th percentile, according to Neuhauser et al. was found in $8.8 \%$ of our subjects. In $7.8 \%$ of subjects blood pressure was in a high-normal range [26].

Several observational studies demonstrated an association between insulin resistance and carotid intimamedia thickness [22]. In the present study, insulin and HOMA-IR index were significantly associated with cIMT although the association was not significant after adjustment for confounders.

Similarly, our study demonstrated a positive association of total IGF-1 with cIMT at 5 years. This association disappeared after adjustment for confounders but a potential clinical significance of this finding is interesting. Infants with higher IGF-1 concentration in infancy tend to have lower IGF-1 in late adolescence [27], while population studies in adults suggest that lower IGF- 1 levels are associated with increased risk of ischemic heart disease and stroke. Direct mechanisms of such a relation need to be elucidated [28].

Although HDL cholesterol was not associated with cIMT, ApoA1 showed inverse association and the ApoB/ ApoA1 ratio was positively associated with cIMT. This may indicate the role of lipid disorders in arteriosclerosis at such an early age, as ApoA1 (HDL component) is responsible for cholesterol clearance from arteries and ApoB is the protein component of LDL, chylomicrons and very low-density lipoproteins. Contrary to apolipoproteins, the lipoprotein cholesterol was measured in local laboratories. Despite strict laboratory quality control, higher variability of this parameter should be considered. Another difference involving methodological issues is the possibility to use non-fasting blood samples, which is allowed only for apolipoprotein measurements [29].

Epidemiologic studies and clinical trials have demonstrated that the $\mathrm{ApoB} / \mathrm{Apo} \mathrm{A} 1$ ratio, representing the balance between proatherogenic and antiatherogenic lipoproteins, is a better predictor of cardiovascular risk in adults than any of the cholesterol indexes [30, 31]. Juonala et al. suggests that apolipoproteins might have additional value over conventional lipid measurements in pediatric cardiovascular risk assessment [29].

Early Protein Intake and cIMT

\section{Strengths and Limitations}

The strength of our study is its experimental design with randomization, early nutritional intervention and long-term follow-up of a large, cross-country cohort of healthy children. However, the long follow-up was associated with significant cohort attrition. Our drop-out ratio was similar to several other cohorts reported by different authors and suggested as acceptable in the context of long-term follow up studies [32]. Loss to follow up is inevitable with time, even with the best study design and conduct.

Because of a long distance between study centers, no standard inter-center variability analysis was possible to perform. According to an existing evidence, the reproducibility of cIMT ultrasound measurement is quite similar across several studies. With the use of standardized protocols and equipment, the measurement error in the cIMT measurements is estimated for $10-20 \%$ [33]. Despite detailed standard operating procedures, common training sessions for sonographers from all study centers, and final measurements by one trained person, the authors are aware of a bias during image acquisition. However, as children from the high- and low-protein group were randomly distributed, even assuming that there is possible systematic error among study centers, the difference between formula groups should be possible to identify.

Median values of cIMT measured in our cohort were slightly greater, than the reference values for 6 years old children published by Doyon et al. [34].

Due to the methodological issues described earlier, such as lack of an inter-center variability control and a non-standard method of the final measurement, with manual ruler calibration, our results, although sufficient for cIMT comparison between groups within the study may not be adequate for comparison with other studies and reference values.

\section{Conclusions}

Despite existing evidence of the impact of high vs. low early protein intake on increased risk of childhood obesity any longer-term effects on cIMT cannot be detected at 5 years. We speculate that our subjects might be too young to detect a significant change in cIMT in response to an early nutritional intervention. Pubertal development as well as an accumulation of environmental factors over time might play a role in the development of cIMT diversity. 
However, even at this young age in healthy children an association between apolipoprotein profile and carotid intima media thickness can be observed.

\section{Disclosure Statements}

The studies reported herein have been conducted with partial financial support from the Commission of the European Communities, the specific RTD Programme 'Quality of Life and Management of Living Resources', within the 5th Framework Programme, research grants no. QLRT-2001-00389 and QLK1-CT-2002-30582, and the 6th Framework Programme, contract No. 007036. This manuscript does not necessarily reflect the views of the Commission and in no way anticipates the future policy in this area.

The authors declare that they have no competing interests.

\section{Acknowledgments}

The authors thank the participating families and all project partners for their enthusiastic support of the project work.

\section{References}

1 O’Donnell CJ, Elosua R: Cardiovascular risk factors. Insights from Framingham Heart Study. Rev Esp Cardiol 2008;61:299-310.

$\checkmark 2$ McGill HC Jr, McMahan CA, Herderick EE, Malcom GT, Tracy RE, Strong JP: Origin of atherosclerosis in childhood and adolescence. Am J Clin Nutr 2000;72:1307S-1315S.

$\checkmark 3$ Olson RE: Is it wise to restrict fat in the diets of children? J Am Diet Assoc 2000;100:2832.

-4 Holman RL, McGill HC Jr, Strong JP, Geer JC: The natural history of atherosclerosis: the early aortic lesions as seen in New Orleans in the middle of the 20th century. Am J Pathol 1958 34:209-235.

5 Berenson GS, Wattigney WA, Tracy RE, Newman WP 3rd, Srinivasan SR, Webber LS, Dalferes ER Jr, Strong JP: Atherosclerosis of the aorta and coronary arteries and cardiovascular risk factors in persons aged 6 to 30 years and studied at necropsy (The Bogalusa Heart Study). Am J Cardiol 1992;70:851858.

6 Tuzcu EM, Kapadia SR, Tutar E, Ziada KM, Hobbs RE, McCarthy PM, Young JB, Nissen SE: High Prevalence of coronary atherosclerosis in asymptomatic teenagers and young adults: evidence from intravascular ultrasound. Circulation 2001;103:2705-2710.

-7 Berenson GS, Srinivasan SR, Nicklas TA: Atherosclerosis: a nutritional disease of childhood. Am J Cardiol 1998;82:22T-29T.

8 Evelein AM, Geerts CC, Visseren FL, Bots ML, van der Ent CK, Grobbee DE, Uiterwaal CS: The association between breastfeeding and the cardiovascular system in early childhood. Am J Clin Nutr 2011;93:712-718.

$\checkmark 9$ Pedersen TR, et al; Scandinavian Simvastatin Survival Study Group: Randomised trial of cholesterol lowering in 4444 patients with coronary heart disease: the Scandinavian Simvastatin Survival Study (4S). Lancet 1994; 344:1383-1389.

10 Koletzko B, von Kries R, Closa R, Escribano J, Scaglioni S, Giovannini M, Beyer J, Demmelmair H, Gruszfeld D, Dobrzanska A, Sengier A, Langhendries JP, Rolland Cachera MF,
Grote V: Lower protein in infant formula is associated with lower weight up to age $2 \mathrm{y}$ : a randomized clinical trial. Am J Clin Nutr 2009;89:1836-1845.

11 Weber M, Grote V, Closa-Monasterolo R, Escribano J, Langhendries JP, Dain E, Giovannini M, Verduci E, Gruszfeld D, Socha P, Koletzko B; European Childhood Obesity Trial Study Group: Lower protein content in infant formula reduces BMI and obesity risk at school age: follow-up of a randomized trial. Am J Clin Nutr 2014;99:10411051.

12 Simşek E, Balta H, Balta Z, Dallar Y: Childhood obesity-related cardiovascular risk factors and carotid intima-media thickness. Turk J Pediatr 2010;52:602-611.

13 Li S, Chen W, Srinivasan SR, Bond MG, Tang R, Urbina EM, Berenson GS: Childhood cardiovascular risk factors and carotid vascular changes in adulthood: the Bogalusa Heart Study. JAMA 2003;290:22712276.

14 Evelein AM, Visseren FL, van der Ent CK, Grobbee DE, Uiterwaal CS: Excess early postnatal weight gain leads to thicker and stiffer arteries in young children. J Clin Endocrinol Metab 2013;98:794-801.

15 Bayes-Genis A, Conover CA, Schwartz RS: The insulin-like growth factor axis: a review of atherosclerosis and restenosis. Circ Res 2000;86:125-130.

16 Kim ES, Park JH, Lee MK, Lee DH, Kang ES, Lee HC, Jekal Y, Jeon JY: Associations between Fatness, Fitness, IGF and IMT among Obese Korean Male Adolescents. Diabetes Metab J 2011;35:610-618.

17 European Commission: Commission Directive 91/321/EEC of 14 May 1991 on infant formulae and follow-on formulae. Off $\mathrm{J}$ Eur Union, 1991, pp 35-49.

18 De Onis M, Onyango AW, Van den Broeck J, Chumlea WC, Martorell R: Measurement and standardization protocols for anthropometry used in the construction of a new international growth reference. Food Nutr Bull 2004; 25:S27-S36.
19 Matthews DR, Hosker JP, Rudenski AS, Naylor BA, Treacher DF, Turner RC: Homeostasis model assessment: insulin resistance and beta-cell function from fasting plasma glucose and insulin concentrations in man. Diabetologia 1985;28:412-419.

20 Gunes T, Koklu E, Yikilmaz A, Ozturk MA, Akcakus M, Kurtoglu S, Coskun A, Koklu S: Influence of maternal smoking on neonatal aortic intima-media thickness, serum IGF-I and IGFBP-3 levels. Eur J Pediatr 2007;166: 1039-1044.

-21 Tamura H, Suzue T, Jitsunari F, Hirao T: Evaluation of carotid arterial intima-media thickness (IMT) and its relation to clinical parameters in Japanese children. Acta Med Okayama 2011;65:21-25.

22 Lamotte C, Iliescu C, Libersa C, Gottrand F: Increased intima-media thickness of the carotid artery in childhood: a systematic review of observational studies. Eur J Pediatr 2011; 170:719-729.

23 Cole TJ, Bellizzi MC, Flegal KM, Dietz WH: Establishing a standard definition for child overweight and obesity worldwide: international survey. BMJ 2000;320:1240-1243.

24 D’Agostino RB Sr, Pencina MJ, Massaro JM, Coady S: Cardiovascular disease risk assessment: insights from Framingham. Glob Heart 2013;8:11-23.

25 Litwin M, Trelewicz J, Wawer Z, Antoniewicz J, Wierzbicka A, Rajszys P, Grenda R: Intimamedia thickness and arterial elasticity in hypertensive children: controlled study. Pediatr Nephrol 2004;19:767-774.

26 Neuhauser HK, Thamm M, Ellert U, Hense HW, Rosario AS: Blood pressure percentiles by age and height from nonoverweight children and adolescents in Germany. Pediatrics 2011;127:e978-e988.

27 Larnkjaer A, Ingstrup HK, Schack-Nielsen L, Hoppe C, Mølgaard C, Skovgaard IM, Juul A, Michaelsen KF: Early programming of the IGF-I axis: negative association between IGF$\mathrm{I}$ in infancy and late adolescence in a 17-year longitudinal follow-up study of healthy subjects. Growth Horm IGF Res 2009;19:82-86. 
28 Kawachi S, Takeda N, Sasaki A, Kokubo Y, Takami K, Sarui H, Hayashi M, Yamakita N, Yasuda K: Circulating insulin-like growth factor- 1 and insulin-like growth factor binding protein-3 are associated with early carotid atherosclerosis. Arterioscler Thromb Vasc Biol 2005;25:617-621.

29 Juonala M, Viikari JS, Kähönen M, Solakivi T, Helenius H, Jula A, Marniemi J, Taittonen L, Laitinen T, Nikkari T, Raitakari OT: Childhood levels of serum apolipoproteins $B$ and A-I predict carotid intima-media thickness and brachial endothelial function in adulthood: the cardiovascular risk in young Finns study. J Am Coll Cardiol 2008;52:293-299.
30 Sierra-Johnson J, Romero-Corral A, Somers VK, Lopez-Jimenez F: The apolipoprotein b/ apolipoprotein AI ratio in the metabolic syndrome-should we start using it? J Cardiometab Syndr 2008;3:53-54.

31 Sniderman AD, Kiss RS: The strengths and limitations of the apoB/apoA-I ratio to predict the risk of vascular disease: a Hegelian analysis. Curr Atheroscler Rep 2007;9:261265.

32 Fewtrell MS, Kennedy K, Singhal A, Martin RM, Ness A, Hadders-Algra M, Koletzko B, Lucas A: How much loss to follow-up is acceptable in long-term randomised trials and prospective studies? Arch Dis Child 2008;93: 458-461.
33 Bots ML, Dijk JM, Oren A, Grobbee DE: Carotid intima-media thickness, arterial stiffness and risk of cardiovascular disease: current evidence. J Hypertens 2002;20:23172325.

34 Doyon A, Kracht D, Bayazit AK, Deveci M, Duzova A, Krmar RT, Litwin M, Niemirska A, Oguz B, Schmidt BM, Sözeri B, Querfeld U, Melk A, Schaefer F, Wühl E; 4C Study Consortium: Carotid artery intima-media thickness and distensibility in children and adolescents: reference values and role of body dimensions. Hypertension 2013;62: 550-556. 